\title{
GUIDEPOSTS FOR ADULT INSTRUCTION
}

\author{
By Gale Jensen \\ Professor of Adult Education, University of Micbigan
}

\begin{abstract}
$A^{n}$ DULT learning takes place in two general types of educational situations. The first can be identified as "natural" societal settings. In these kinds of situations the acquisition of new behaviors is the result of day-today participation in societal activities.
\end{abstract}

The second can be designated as formal instruction carried on under the auspices of an agency (e.g., a school) which is assigned the special task of inducing the development of new behaviors. Learning in these situations is the result of participation in a specifically created and designed "learning" community in which certain kinds of instructional methodologies and techniques are deliberately employed to obtain certain results.

In the first general type of educational situation, newly acquired behaviors are unforeseen and promiscuously developed by-products. The kind of learning which emerges is largely a matter of chance. The acquisition of new behavior may leave the adult better able to take part effectively in life's affairs, or the new behaviors may reduce his effectiveness and in some cases literally cripple him so far as his ability to maintain his position as an adult citizen is concerned.

Under the second general type of educational situation, goals pertaining to the new behaviors to be learned are set forth. The socio-psychological phenomena which are involved in attaining these goals are then controlled and manipulated in ways which promise the greatest amount of certainty and efficiency for goal attainment.

\section{Formal Instruction}

Large-scale, complex, industrial societies, characterized by rapid social change, can never rely upon the first mentioned general type of educational situation to develop the kind of behaviors needed by its citizens. Unpredictable, promiscuously developed behavior is likely to produce more social and personal difficulties than society can solve. The reliance upon the second general type of educational situation, formal instruction, therefore, becomes one of the characteristics most likely to be found in these kinds of societies.

Examination of these societies reveals that formal instruction programs are not limited or confined to those organizations designated as schools, colleges, and universities. Rather, one finds that provision for formal instruction is an integral part of military, business and industrial, religious, governmental, medical, and voluntary organizations and groups as well.

Under these societal conditions there is a great involvement of adults in formal instructional activities. The 
more complex and specialized the socity, the higher the formal instruction requirements will be. Furthermore, under these conditions, the adult will not function in the traditional role of "student." Rather, his participation in formal instructional activities will be done while he holds some functioning governmental or occupational role. This means that his authority and power relationships with the teacher will be greatly different than those of the traditional student. Also, under these conditions, the effectiveness of instruction will be evaluated in terms of its instrumental worth, and because of its closeness to operating situations, effectiveness for producing the needed behaviors will be subject to immediate testing and change.

All of this means that formal adult instruction is characterized by the systematic formulation of learning objectives which take account of and are based upon judgments about societal requirements, the importance of certain cultural values, and the needs of individuals. It also means that the socio-psychological phenomena associated with formal adult instruction must be conceptually organized and understood if it is to be managed or controlled in whatever ways may be required to achieve a chosen or given set of learning objectives. The main purpose of this paper is to identify and define these socio-psychological elements and to formulate a set of principles which makes possible the systematic analysis and management of adult instruction needed for the achievement of given learning objectives.

Assumptions that are more or less unconsciously held about two kinds of psychological conditions that "should" prevail in formal instructional situations need to be identified at this point. These assumptions are manifestations of two value norms present in western cultures. The first is that learners should achieve the greatest amount of behavioral development possible within the minimum time required for this development. This is the efficiency criterion of maximum output or return for minimum input or effort. The second is that learners should be kept psychologically involved in the instructional situation to the highest degree possible; a "good" instructional situation is one in which the learners are always highly interested and extending the fullest effort to learn. This is a reflection of the Protestant ethic as it pertains to the significance of work and production for life.

These two value norms shape educational practice, particularly in the United States. Their significance and effect upon people who participate in formal instruction activities never have been investigated thoroughly, if at all. Nevertheless, these two values act as "constants" which dominate the formulation of curriculums and instructional procedures. Practically all experimental studies on the effectiveness of instructional or teaching methods are designed around these two societal values. Practically all hypotheses about and principles for controlling human learning are formulated in terms of "maximum involvement and achievement."

The principles stated in this paper, also, are formulated in keeping with these two values. They are, therefore, rules for guiding action in which certain value preferences are implicit. As such, they represent a specific applica- 
tion of more formal and descriptive propositions about human learning which may have been formulated according to hypothetical or inductive, empirical methods of inquiry.

It, also, should be recognized that to always make these "value demands" upon a formal instructional situation may produce an opposite effect. Adult students are not always interested in maximizing their learning or become "totally" involved in each instructional situation in which they take part. Rather, they are inclined to distribute their energy and involvement according to the kind and amounts of learning they feel would be most beneficial immediately and for the future. Specifically, this means that if they are desirous of only a small amount of learning in a given area, they will become only slightly involved in the instructional activity associated with it and will resist efforts on the part of the teacher and other students to maximize learning and become totally involved.

\section{Three Objectives}

The objectives of this article are three in number. First, it will present an account of the basic dynamics of socio-psychological forces present in all formal adult instructional situations. Second, it will provide an identification and definition of the sociopsychological interactions which take place between adults during formal instruction and which determine the kind of learning that will result. Third, it will present a set of principles for guiding or managing these socio-psychological interactions in ways which maximize the probabilities of achieving stipulated instructional objectives.

\section{Dynamics of Formal Adult Instructional Situations}

Two general kinds of socio-psychological forces are inherent to the dynamics of adult instruction. One kind emanates from the social system which organizes and conducts the instruction. The other kind emanates from the personality needs of the adults and those who instruct them.

Formal instruction for adults is organized and carried on both by communities and large-scale formal organizations. The systems of education these two kinds of social entities create and utilize are as necessary for their survival as they are for providing for the personal well-being of their members.

Both communities and large-scale formal organizations, therefore, impose on their respective educational systems a three-fold task. They require that formal instruction which teaches individuals the ways of the community or formal organization. They require individuals be taught knowledges and skills which enable them to provide for their personal needs. They require instruction which enables their respective members to solve persisting and perplexing problems of the community or the formal organization.

These tasks, which communities and formal organizations stipulate for their systems of education, produce one set of forces inherent to the basic dynamics of formal adult instruction. They particularly influence the kind of instructional objectives that are chosen.

Once a community or formal organization has established an educational system to take care of its sur- 
vival needs, attention must be given to maintaining the integrity of the educational system itself. Incidents which are disrupting to the educational system and threaten its order and smooth operation must be analyzed and controlled.

In brief, the educational system develops a set of organizational needs that must be met if it is to effectively contribute to the life of the community or formal organization of which it is a part. This means that a set of social controls must be established. These controls stipulate the kind of behavior which is required in the educational system to insure its continuance in a state of good order. Most often these social controls take the form of administrative rules. As such, they introduce another set of forces which make up the basic dynamics of adult instruction.

The adult's needs for self-growth and development, the achievement of social worth and success, and the establishment of intimate, personal relations with other persons act as a third set of forces contributing to the dynamics of formal instruction.

Adults are especially concerned with maintaining and enhancing their social work and success. This is probably the primary source of motivation of adult learning for many years of adult life. This, in turn, in the American society, is dependent on continued increase of competence. Adults, therefore, have a strong need for the acquisition of new knowledges and skills in an instructional situation in which there is no danger of losing "hardwon" prestige. The instructional enterprise represents high risks, however, because of the possibilities that a public display of ignorance may lead to a loss of prestige and social worth. The instructor's need for selfgrowth, prestige as an expert, and his assigned responsibilities for carrying out the administrative rules of the educational system act as the fourth set of forces contributing to the dynamics of formal adult instruction. Instructors often have as strong (or stronger) needs to learn as the adult students. In brief, they have expectations about chances for learning just as the adult students do and, because of the authority assigned to them by the educational system, they are able to exert strong influences upon the instructional activities of an adult group.

They, also, have need to demonstate their expertness and social worth for purposes of winning public recognition, promotions, and raises in pay. This, too, can greatly shape the instructional dynamics which emerge. To complicate matters, these needs of the instructor are sometimes frustrated by the responsibilities placed upon him for carrying out the administrative rules which have been established to insure order in and continuity of the educational system.

\section{Types of Socio-Phychological Interactions Affecting Adult Learning}

There are a number of socio-psychological interactions which take place between adults in formal instructional situations. The first type of these can be identified as problemsolving and task interactions. It is this type of interaction which is indigenous to the development of new behaviors as stated in the instructional objectives for a group of adults. Instructional activities formulated by an 
instructor endeavor to specify what experience and interactions are necessary to achieve the new learnings or behaviors. Each time an adult student attempts to participate in the planned instructional activities of a group, he initiates a problem-solving interaction with some other member or members of the group. He may initiate an interaction which facilitates the learning progress, or he may initiate interactions which impede it. It is for this reason that the instructor attempts to control these interactions so as to accomplish the instructional objectives in the most effective and efficient way. It is for this reason that socio-psychological principles for guiding adult instruction are so important to adult education practice.

A second type of interaction which takes place between adult students in formal instructional situations has to do with decision-making. Adult instructional groups are constantly confronted with making decisions about such things as the best instructional procedures to follow, the kind of learning goals which would be most beneficial, length of time for assignments, policies about examinations, bases for giving grades, and the amount of informal, friendship activities to let develop within the group.

Adults are especially sensitive to the way these decisions are made. When decisions are made that increase or decrease these kinds of interactions to too great a degree, the problem-solving and task interactions necessary to acquiring the learning objectives can be affected adversely. It is this type of interaction that is likely to make instructors most anxious and to use their authority to control these interactions.
Principles for guiding and managing these types of interactions are a necessity for an effective adult education practice.

A third kind of interaction that takes place in formal instructional situations pertains to adults' efforts to influence one another to behave in one way rather than another. Each adult student and instructor has some power to reward and punish others. This power is used at times to obtain more favorable conditions or to prevent conditions not wanted. Interactions of this kind sometimes lead to more effective problem-solving and task interactions; at other times they debilitate problem-solving interactions and reduce the probabilities of attaining the new behavior specified by the instructional objectives. For this reason, the instructor of adults must be aware of these kinds of interactions and able to guide them in a way which facilitates rather than impedes the necessary problem-solving and task interactions.

A fourth type of interaction that can take place between adult students is based on their personal evaluations of one another. Because adults are especially sensitive to maintaining and enhancing their social worth and successes, they are inclined to make careful assessments of one another before initiating interaction. On the basis of these assessments, some persons may be socially acceptable and eligible for interaction, while others may not. The effect of these interactions is to reveal which persons are acceptable to one another and to create sub-groups in an instructional situation. The management or guidance of these types of interactions, therefore, is highly significant for the instructor. If this type of interaction fractionates an instruc- 
tional group and sets up barriers between its adult members, the probabilities of creating effective problemsolving and task interactions are greatly reduced.

\section{Need to Share Perceptions}

The fifth type of socio-psychological interaction that develops between adults involved in formal instruction is related to their need to share personal or private perceptions and feelings with one another. The instructional enterprise, if effective, is likely to produce strong inner reactions in the learner. A need to examine and assess these personal reactions to the instructional experience thus results. The gratification of this need requires interaction with another person or persons which permits a safe and confidential examination of private reactions to the instructional experience. Successful handling of these kinds of interactions by an instructor is a requisite to maintaining effective problem-solving and task interactions.

\section{Guiding Principles}

The principles outlined below will provide (1) statements about the general socio-psychological conditions which need to prevail in the formal instructional situation, and (2) statements pertaining to the guidance and control of the different types of interactions which take place during formal instruction.

A. Principles pertaining to the general socio-psychological conditions for effective formal instruction.

1. A balance must be maintained between the various types of sociopsychological interactions which insure that most of the energies of adult students and instructor are channeled into problem-solving and task interactions.

2. The psychological tension level of adult learners must be established and maintained at that level which permits the release of energy into problem-solving and task interactions at a rate required by the learning tasks and objectives.

3. Group pressures and norms which develop to regulate the behavior of adult learners must be guided and controlled by the instructor to make certain that they do not inhibit full participation in the instructional enterprise.

4. Adult learners must assume full responsibility for their participation in the instructional enterprise in a manner which provides the most effective contributions toward achieving the instructional goals.

5. Disruptive behavior by an adult learner must be perceived by the instructor and other members of an adult instructional group as a manifestation of a deficient learning situation until other data show conclusively that the behavior results from some form of deviate personality organization.

B. Principles concerning the guidance and control of problem-solving and task interactions.

1. Instructional goals proposing new behaviors for adults must be formulated in keeping with the personal needs and life situations of adults participating in formal instruction.

2. The gratifications or rewards adults experience in formal instruction situations must result primarily from the acquisition of new be- 
haviors rather than from gratifications received from prestige, influence, and friendship interactions.

3. The development of multiple learning goals for adult instruction must be permitted to the point (1) that the group is still able to function effectively as a group, and (2) that the fulfillment of individual learning needs is promised.

4. Cooperative (rather than competitive) problem-solving interactions must be developed between adult learners if the probabilities for the achievement of instructional goals are to be maximized.

5. The problem-solving interactions between adult students must provide for the use of objective, public methods for evaluating learning progress.

C. Principles concerning the guidance and control of decision-making interactions.

1. The authority and decisionmaking interactions between adult students and the instructor must be such that the adult students do not experience a loss of adult autonomy.

2. Adults must be free to decide to leave a formal instructional group whenever the learning experiences fail to contribute to their personal needs or to the problems present in their life situations.

3. The instructional and evaluation procedures used in adult instructional groups must be assessed and then accepted or rejected by the adult students themselves to whatever degree they possess knowledges and skills to make these decisions.

4. Adults must be free to assess and reject or accept the expert knowledge of the instructor in light of the realities of their life experiences.

5. The level of aspiration or amount of learning proposed for a given time for an adult instructional group must represent a decision which reflects the feelings and wishes of the adult members.

6. Decisions to change the aspirational level for new learnings should be based on interactions which re-evaluate the instructional enterprise in light of the learning progress actually taking place.

7. Dependency relations between adult students and instructor must be permitted and maintained only so long as a student does not possess the skills for successfully performing or accomplishing a given learning task.

8. Adult learners must be free to decide whether they can or cannot effectively take part in a given learning venture.

D. Principles concerning social influence interactions.

1. Adult students must be able to influence the kind of learning goals chosen for the instructional group as a means of making certain that these goals take account of their needs and problems.

2. The instructor must not use his authority in a coercive or arbitrary manner should adults disagree with proposed learning goals or instructional procedures.

3. Adult learners must be free to influence the character and direction of the problem-solving and task interactions of the instructional group whenever they possess the skill and inclination to do so. 
4. Aggressive reactions by adult students to the ideas, values, and actions contained in the instructional activities must be permitted by the instructor.

E. Principles concerning social acceptance and personal evaluation interactions.

1. Adult students must have full social acceptance by the instructor and fellow students for full release of energy for learning.

2. The learning tasks designed for adult students must be commensurate with the study skills they possess so as not to confront them with a situation in which a loss of personal esteem is likely to result.

3. Adult students must be given an opportunity (devoid of loss of personal esteem and social acceptability) to realistically determine their present level of development with respect to a proposed learning goal.
4. No disrespect must be shown to adult students who feel that they are unable or not "ready" to participate in a learning venture. (This must be a group standard about participation.)

F. Principles concerning informal, private interactions.

1. Adult students must be free to have informal, private interactions with one another whenever the content of these interactions are concerned with experiences resulting from the problem-solving and task interactions.

2. Informal, private interactions must lead to the correction of personal disturbances of individual students rather than to the development of organized resistances.

3. The instructor must encourage individual students to share the content of the informal, private interactions with him and other students whenever they feel it safe to do so.

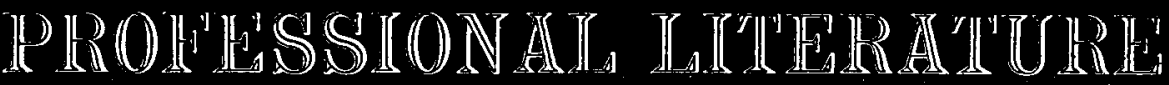

(Review Editor, Coolie Verner, Florida State University)

\section{DOES WE MEAN US?}

The Overstreets have written a book.* That is not news. If they had not written a book, it would be news indeed. Their book is on the best seller list-another fact that does not surprise us. It has been much and favorably reviewed. Any book by the

\footnotetext{
*W HA T W E M UST KN O W ABOUT COMMUNISM-Its Beginnings-Its Growtb-Its Present Status. By Harry and Bonaro Overstreet. New York: $W . W$. Norton and Company. 1958. 348 pp. \$3.95.
}

Overstreets would be and should be. It has been-and is-being much discussed. Another review or further discussion now may seem superflous or even tiresome repetition of what everybody knows.

It has already been ably reviewed for members and friends of AEA in AdUlt Leadership, January, 1959. There we find an excellent indication of content, approach, and general philosophy which will not be repeated here.

When asked to review What We 